\title{
Risk of severe hematologic toxicities in cancer patients treated with PARP inhibitors: results of monotherapy and combination therapy trials
}

This article was published in the following Dove Press journal: Drug Design, Development and Therapy

\author{
Iulian Alecu \\ Tsveta Milenkova \\ Simon R Turner \\ Research and Development, \\ AstraZeneca UK Limited, Cambridge, \\ UK
}

Correspondence: Simon R Turner Research and Development, AstraZeneca UK Limited, GRAPSQA Milstein Building, Granta Park, Cambridgeshire, CB2I 6GH, UK Email simon.turnerI@astrazeneca.com

\section{Dear editor}

The tolerability profile of PARP inhibitors often includes hematologic toxicities, and the characterization of these adverse events is important to allow effective management by clinicians. Zhou et $\mathrm{al}^{1}$ recently carried out a meta-analysis of the incidence and relative risks of severe neutropenia, thrombocytopenia, and anemia events in 12 randomized controlled trials of PARP inhibitors, either as monotherapy or in combination with chemotherapy or radiotherapy. The authors concluded that olaparib resulted in a higher incidence of severe (common terminology criteria for adverse events [CTCAE] grade $\geq 3$ ) neutropenia when compared with niraparib and veliparib; however, these conclusions are based on inappropriate and incomplete comparisons of hematologic toxicity with olaparib or veliparib in combination with myelotoxic chemotherapy versus niraparib monotherapy. While both monotherapy and combination therapy olaparib studies are discussed in the paper, the neutropenia analysis is based on olaparib data solely from studies in combination with paclitaxel or paclitaxel plus carboplatin. In order to inform the practicing clinician of the relative risk of hematologic toxicity associated with different PARP inhibitors, direct comparison needs to be conducted based on monotherapy, where applicable, as per the approved drug indication, otherwise the reader is given misleading information.

Consistent with the known myelotoxicity of carboplatin and paclitaxel, the observed incidence of severe neutropenia in studies of olaparib monotherapy is considerably lower than the figure Zhou et $\mathrm{al}^{1}$ have derived from combination trials (olaparib combination arm, 49.1\%; chemotherapy control arm, 36.5\%). In each of three pivotal registration trials of olaparib monotherapy, the incidence of severe (CTCAE grade $\geq 3$ ) neutropenia was less than $10 \%$ (SOLO2 and OlympiAD data include decreased granulocyte count, decreased neutrophil count, febrile neutropenia, granulocytopenia, neutropenia, neutropenic infection [OlympiAD only] and neutropenic sepsis). In Study 19 (NCT00753545), a randomized controlled trial of 265 platinum-sensitive recurrent ovarian cancer patients, the incidence of severe neutropenia was $3.7 \%$ for olaparib treated-patients (placebo arm, 0.8\%). ${ }^{2}$ In the SOLO2 study (NCT01874353), which recruited 295 platinum-sensitive recurrent ovarian cancer patients with a $B R C A$ mutation, the incidence was $5.1 \%$ (placebo arm, $4.0 \%$ ), ${ }^{3}$ while $9.3 \%$ of the $205 B R C A$ mutated metastatic breast cancer patients treated with olaparib monotherapy in the 
OlympiAD trial (NCT02000622) experienced grade $\geq 3$ neutropenia compared with $26.4 \%$ of 97 patients in the chemotherapy comparator arm.

These grade $\geq 3$ neutropenia data compare favorably against the niraparib monotherapy data (19.6\% incidence compared with $1.7 \%$ in the control arm) and veliparib combination therapy data $(29.9 \%$ incidence compared with $10.3 \%$ in the control arm) discussed by Zhou et al, ${ }^{1}$ which suggest that it is inaccurate to conclude that olaparib resulted in higher incidence of neutropenia when compared with niraparib and veliparib. ${ }^{4}$

\section{Acknowledgment}

We thank Elin Pyke, MChem, of Mudskipper Business Ltd, for medical writing assistance, funded by AstraZeneca.

\section{Disclosure}

IA, TM, and SRT are employees of AstraZeneca, and TM and SRT own stock. The authors report no other conflicts of interest in this communication.

\section{References}

1. Zhou JX, Feng LJ, Zhang X. Risk of severe hematologic toxicities in cancer patients treated with PARP inhibitors: a meta-analysis of randomized controlled trials. Drug Des Devel Ther. 2017;11:3009-3017.

2. Gourley C, Friedlander M, Matulonis UA, et al. Clinically significant long-term maintenance treatment with olaparib in patients with platinumsensitive relapsed serous ovarian cancer. J Clin Oncol. 2017;35:5533.

3. Pujade-Lauraine E, Ledermann JA, Selle F, et al. Olaparib tablets as maintenance therapy in patients with platinum-sensitive, relapsed ovarian cancer and a BRCA1/2 mutation (SOLO2/ENGOT-Ov-21): a doubleblind, randomised, placebo-controlled, phase 3 trial. Lancet Oncol. 2017; 18:1274-1284.

4. Robson M, Im SA, Senkus E, et al. Olaparib for metastatic breast cancer in patients with a germline BRCA mutation. $N$ Engl J Med. 2017;377: $523-533$.

Dove Medical Press encourages responsible, free and frank academic debate. The content of the Drug Design, Development and Therapy 'letters to the editor' section does not necessarily represent the views of Dove Medical Press, its officers, agents, employees, related entities or the Drug Design, Development and Therapy editors. While all reasonable steps have been taken to confirm the content of each letter, Dove Medical Press accepts no liability in respect of the content of any letter, nor is it responsible for the content and accuracy of any letter to the editor.

\section{Publish your work in this journal}

Drug Design, Development and Therapy is an international, peerreviewed open-access journal that spans the spectrum of drug design and development through to clinical applications. Clinical outcomes, patient safety, and programs for the development and effective, safe, and sustained use of medicines are the features of the journal, which has also been accepted for indexing on PubMed Central. The manuscript management system is completely online and includes a very quick and fair peer-review system, which is all easy to use. Visit http://www.dovepress.com/testimonials.php to read real quotes from published authors. 